\title{
COVID 19 E EDUCAÇÃO: RESISTÊNCIAS, DESAFIOS E (IM)POSSIBILIDADES
}

\author{
COVID 19 AND EDUCATION: RESISTANCE, CHALLENGES AND \\ (IM)POSSIBILITIES
}

\section{COVID 19 Y EDUCACIÓN: RESISTENCIA, DESAFÍOS Y (IM)POSSIBILIDADES}

\author{
Andreia Cristina Freitas Barreto ${ }^{\mathrm{i}}$ \\ Daniele Santos Rocha ${ }^{\text {ii }}$
}

\begin{abstract}
Resumo: Com o COVID-19, a volta à normalidade não apresenta soluções fáceis, a vida social, educacional e econômica estão sendo extremamente afetadas. Com a Pedagogia Pandêmica, as formas de se relacionar, de consumir, as estratégias de trabalhos e, sobretudo, o trabalho docente foram impactados. Diante desse cenário, esse estudo bibliográfico e documental objetiva tecer reflexões sobre os impactos e desafios do COVID-19 na Educação. Os resultados mostraram que muitos são os desafios e (im)possibilidades para a prática docente no atual contexto, observa-se que os professores e professoras são mais consumidores da tecnologia que produtores. Esse fato se deve ao modelo de formação inicial que precisa ser pensado/adaptado para as demandas da contemporaneidade. A Educação a Distância $(\mathrm{EaD})$ precisa ser configurada como espaço de democratização. Muitos alunos e alunas não possuem acesso à internet e não dispõem de espaço adequado para o desenvolvimento de estudos nas residências.
\end{abstract}

\begin{abstract}
With COVID-19, the return to normality does not present easy solutions, social, educational and economic life are being extremely affected. With Pandemic Pedagogy, the ways of relating, consuming, work strategies and especially teaching work, were impacted. In view of this scenario, this bibliographic and documentary study aims to reflect on the impacts and challenges of COVID - 19 in Education. The results showed that there are many challenges and (im) possibilities for teaching practice in the current context, it is observed that teachers are more consumers of technology than producers. This fact is due to the initial training model that needs to be thought out / adapted, for the demands of contemporary times. Distance education Bneeds to be configured as a space for democratization. Many students do not have access to the internet and do not have adequate space for the development of studies in homes.
\end{abstract}

Resumen: Con COVID-19, el retorno a la normalidad no presenta soluciones fáciles, la vida social, educativa y económica se está viendo extremadamente afectada. Con la pedagogía pandémica, las formas de relacionarse, consumir, estrategias de trabajo y especialmente el trabajo de enseñanza se vieron afectadas. En vista de este escenario, este estudio bibliográfico y documental tiene como objetivo reflexionar sobre los impactos y desafíos de COVID - 19 en Educación. Los resultados mostraron que existen muchos desafíos y $(\mathrm{im})$ posibilidades para la práctica docente en el contexto actual, se observa que los maestros son más consumidores de tecnología que productores. Este hecho se debe al modelo de entrenamiento inicial que necesita ser pensado / adaptado, para las demandas de los tiempos contemporáneos. La educación a distancia debe configurarse como un espacio para la democratización. Muchos estudiantes no tienen acceso a internet y no tienen el espacio adecuado para el desarrollo de estudios en el hogar.

Palavras-chave: COVID-19; Educação; Ensino a distância.

Keywords: COVID-19; Education; Distance learning.

Palabras claves: COVID-19; Educación; Aprendizaje a distancia. 


\section{INTRODUÇÃO}

Em 31 de dezembro de 2019, surge na cidade de Wuhan, província de Hubei, República Popular da China, ocorrências de casos de pneumonia na cidade. Naquele momento, a OMS foi notificada a fim de verificar as recorrências dos casos. Logo, foi identificado o agente transmissor, tratando-se de um novo coronavírus: SARS-CoV-2, que pode levar à síndrome respiratória aguda, hospitalização e morte.

A partir do dia 12 de março de 2020, o surto global de SARS-CoV-2 foi declarado como uma pandemia, com 125.048 casos e 4.613 mortes, atingindo 117 países e territórios em todo o mundo. De acordo com Freitas, Donaliso e Napimogal (2020), não existe muita clareza sobre vários aspectos epidemiológicos da doença que se espalhou rapidamente pelo mundo, mas já se sabe uma forma de combatê-la: é testando em massa e isolando pelo menos $80 \%$ dos contaminados.

Com a pandemia, a volta à normalidade não apresenta soluções fáceis, a vida social, educacional e econômica, estão sendo extremamente afetadas. O mundo hoje presencia uma nova forma de comportamento social, com a Pedagogia Pandêmica, as formas de se relacionar, de consumir, as estratégias de trabalhos e, sobretudo, o trabalho docente foram impactados.

Com esse cenário, a educação em época de COVID-19 passa a entender a tecnologia como um espaço de luta, transformação, mas também de desigualdades. Diante desse desafio, com base em alguns estudos e documentos legais da Educação, esse texto objetiva tecer reflexões sobre os impactos e desafios do COVID-19 na Educação. Para tanto, o presente estudo emergiu em um questionamento que norteou o desenvolvimento do mesmo, a saber: Quais são os impactos e desafios do COVID-19 na Educação?

\section{O CORONAVÍRUS NO BRASIL E NO MUNDO}

Os primeiros casos de COVID-19 foram identificados em um mercado de frutos do mar e animais vivos na província de Hubei, República Popular da China. De acordo com as práticas realizadas pela OMS, a qual visa nomear novas doenças infecciosas a humanos, a doença recebeu o nome de COVID-19, que faz referência ao tipo de vírus e ao ano que foi iniciada a pandemia (FREITAS; DONALISO; NAPIMOGA, 2020).

No Brasil, o primeiro caso confirmado foi em 26 de fevereiro de 2020, sendo o primeiro resultado positivo da América Latina, segundo dados do Ministério da Saúde, um caso importado vindo de um homem residente de São Paulo, de 60 anos, que retornou de uma viagem da Itália. Após essa confirmação, os números só cresceram, alcançando todas 
as regiões do país. Até o momento, dia 28 de abril de 2020, estima-se que existam 215.138 mil mortes e mais de 3 milhões de pessoas infectadas no mundo, sendo 5.019 mortes e 66.501 casos confirmados no Brasil, com uma taxa de letalidade de 6,8\%. Os números no país não são considerados reais por especialistas, uma vez que o Brasil não possui número de testes suficientes para testagem em massa. Para Santos (2020), os grupos dos países do Sul enfrentarão um surto da pandemia mais discriminatório e difícil, uma vez que estes padecem de uma vulnerabilidade que vem antes da quarentena e que se agrava com ela.

Abaixo (Figura $1^{1}$ ), apresentamos os números das evoluções de casos nos Estados Brasileiros, com destaque para os três estados mais atingidos pela pandemia.

Figura 1- Números de casos por Estados brasileiros

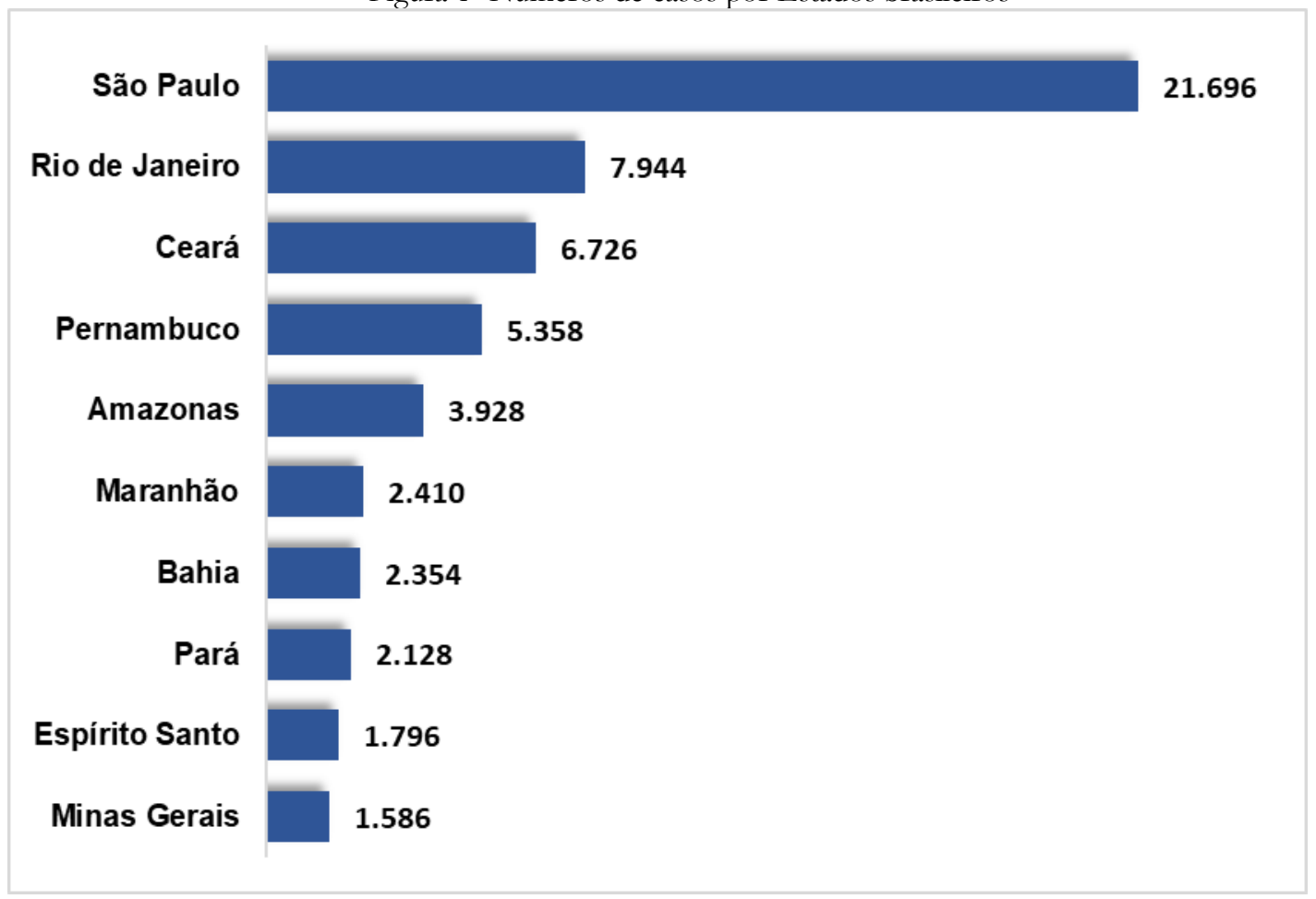

Fonte: Elaborado pelas autoras (2020).

Os estados de São Paulo (21.696), Rio de Janeiro (7.944) e Ceará (6.726) concentram os maiores números de casos, segundo os dados do Ministério da Saúde, correspondendo a mais de 56, 18\% do número de casos de todo país.

Diferente do Brasil, a estratégia de testagem em massa foi utilizada pelos países como a China, Itália e EUA como forma de combater a transmissão do vírus, que tem se mostrado de alto contágio. O isolamento social é um método eficaz e defendido por especialistas, pois desacelera curva de transmissão, evitando colapso no sistema de saúde,

\footnotetext{
1 Figura 1 - Os dados que foram utilizados para construir esse gráfico estão disponíveis em: https://covid.saude.gov.br/ Acessado em: 28/04/20.
} 
conforme advogam Macedo, Ornellas e Bonfim (2020, p. 06), “os processos de redução de infecção em todos os lugares do mundo se dá pelo isolamento e quarentena da sociedade, higienização e medidas para pormenorizar as contaminações".

Os países que aderiram tardiamente ao isolamento apresentaram números maiores de transmissão, enquanto em outros países que fecharam suas fronteiras e se isolaram apresentam melhores números. A tabela representada abaixo, construída através dados da Johns Hopkins University, demonstra o comportamento do número de infectados e mortos durante os 50 dias de pandemia.

Tabela 1: Avanço do Coronavírus nos Países

\begin{tabular}{|c|c|c|c|c|}
\hline País & $\begin{array}{l}\text { Infectados após } 50 \\
\text { dias }\end{array}$ & $\begin{array}{l}\text { Mortos após } 50 \\
\text { dias }\end{array}$ & Infectados até 15/04 & Mortos até 15/04 \\
\hline China & 75.101 & 2.239 & 83.751 & 3.474 \\
\hline EUA & 1.281 & 36 & 636.350 & 28.326 \\
\hline Itália & 47.021 & 4.032 & 165.155 & 21.645 \\
\hline Espanha & 25.374 & 1.375 & 177.644 & 18.708 \\
\hline Brasil & 28.320 & 1.376 & 28.320 & 1.736 \\
\hline França & 3.661 & 79 & 133.470 & 17.167 \\
\hline Alemanha & 1.908 & 3 & 134.753 & 3.804 \\
\hline Japão & 639 & 15 & 8.100 & 146 \\
\hline Coreia do & 8.236 & 75 & 10.591 & 225 \\
\hline
\end{tabular}

Conforme observado na Tabela 1, os números diferenciam-se, pois, cada país apresentou estratégias de distanciamentos distintos, a China adotou medidas mais duras de isolamento e conseguiu estabilizar os números de casos depois de 50 dias. Já a Itália, adotou medidas menos rígidas e viu seu número de mortos ultrapassar a China, só então depois do $53^{\circ}$ dia, com 59 mil casos e 3.476 mortos, que o governo decide fechar os serviços não essenciais no país (MACEDO; ORNELLAS; BONFIM, 2020). Os EUA demoraram para aderir o isolamento e viu, após a testagem em massa, o país virar o novo epicentro da doença com 1 milhão de contaminados, representando 1/3 dos casos no mundo.

Consoante, as medidas de isolamento e assistência à população mais vulnerável mostram-se eficazes para combate à doença. O Brasil tem enfrentado dificuldades de enfrentar a pandemia devido a uma política de afrouxamento do isolamento em detrimento 
da conservação da economia. Macedo, Ornellas e Bonfim (2020) defendem a realização de políticas públicas que tragam resultados positivos para o bem social e saúde da população e destacam, também, a quarentena como única saída de prevenção social dos males causadas por esse vírus. Por outro lado, o isolamento mostra seu lado cruel, como destaca Santos (2020, p. 21): “a quarentena não só torna mais visíveis, como reforça a injustiça, a discriminação, a exclusão social e o sofrimento imerecido que elas provocam”.

\section{ENFRENTAMENTO DA PANDEMIA NA EDUCAÇÃO: OS DISPOSITIVOS LEGAIS E A EDUCAÇÃO A DISTÂNCIA}

Com os números de casos confirmados no Brasil, o então ministro da saúde Luiz Henrique Mandeta ${ }^{2}$, tendo como base nas recomendações da OMS - Organização Mundial da Saúde, sugeriu que os estados adotassem como medida de prevenção a suspensão das aulas em todo país. O então governador do estado da Bahia, Rui Costa, no dia 16 de março, em Decreto Estadual No 19.529, dispôs sobre a suspensão das atividades letivas nas unidades de ensino pública e particular em face ao combate da transmissão da pandemia. Com essa medida, só na rede estadual de ensino, 800 mil alunos estão sem aula.

Segundo o artigo 205 da Constituição Federal de 1988 (BRASIL, 1988), a educação é um direito de todos e dever do estado e da família, com a participação e colaboração da sociedade, visando o desenvolvimento pleno, o preparo do sujeito para exercer a cidadania e para o mercado de trabalho. Diante dessa relevância, como modelo de enfrentamento ao COVID-19, foram publicadas legislações no Brasil (Tabela 2) que apresentam orientações sobre as possibilidades de retorno às atividades curriculares educativas em domicílio.

Tabela 2 - Legislação COVID-19 - Educação

\begin{tabular}{|c|c|}
\hline Portaria $\mathrm{n}^{\circ} 343$, de 17.3 .2020 & $\begin{array}{l}\text { Dispõe sobre a substituição das aulas presenciais } \\
\text { por aulas em meios digitais enquanto durar a } \\
\text { situação de pandemia do Novo Coronavírus - } \\
\text { COVID-19. }\end{array}$ \\
\hline $\begin{array}{l}\text { Conselho Nacional de Educação } \\
\text { - 20. 03. } 2020\end{array}$ & $\begin{array}{l}\text { Proposta de parecer sobre reorganização dos } \\
\text { calendários escolares e realização de atividades } \\
\text { pedagógicas não presenciais durante o período de } \\
\text { pandemia do COVID-19. }\end{array}$ \\
\hline $\begin{array}{l}\text { Resolução CEE BA n. }{ }^{\circ} 27 \text {, de } 25 \\
\text { de março de } 2020\end{array}$ & $\begin{array}{l}\text { Orienta as instituições integrantes do Sistema } \\
\text { Estadual de Ensino sobre o desenvolvimento das } \\
\text { atividades curriculares, em regime especial. }\end{array}$ \\
\hline
\end{tabular}

2 Assumiu a pasta até 16 de abril de 2020.

${ }^{3}$ Disponível em http://www.planalto.gov.br/CCIVIL_03/Portaria/quadro_portaria.htm. Acessado em 30 de abril de 2020.

${ }^{4}$ Disponível em: Portal.mec.gov.br. Acessado em 30 de abril de 2020.

${ }^{5}$ Disponível em: Portal. mec.gov.br. Acessado em 30 de abril de 2020. 
Conselho Nacional de Educação - 28. 04. 2020
CNE aprova Diretrizes para escolas durante a pandemia. O documento apresenta orientações e sugestões para a educação básica e ensino superior.

Fonte: Elaborado pelas autoras (2020).

Diante do exposto, na tabela 2 observa-se que assim como os outros países, o Brasil publicou legislações que versam sobre possibilidades de realização de atividades pedagógicas por meio do Ensino a Distância. A possibilidade de desenvolvimentos de atividades a distância não é tão recente, o Decreto-Lei no 1.044 , artigo $2^{\circ}$ de 21 de outubro de 1969 (BRASIL, 1969) já apresentava possibilidades de atendimento e o acesso de alunos a atividades curriculares como forma de compensação em ausência das aulas, nos seus domicílios.

A preocupação maior nesse momento é cumprir a quantidade de dias letivos e a nova forma de como o calendário escolar será reorganizado, considerando também a Lei de Diretrizes e Bases da Educação Nacional - LDB 9394/96 (BRASIL, 1996), que dispõe de uma carga horária de 800 horas para o ensino médio e fundamental distribuídos em 200 dias letivos. Já para o Ensino Superior, são 200 dias letivos, conforme artigo 47. No entanto, as medidas tomadas pelo governo do estado da Bahia estão justificadas no artigo 36 da mesma lei, no inciso 11, o qual afirma que a educação poderá ser exercida por meio de educação a distância ou presencial mediada por tecnologias, sendo essa modalidade supervisionada por uma equipe pedagógica e contida nos projetos pedagógicos.

Além disso, de acordo com o parecer $N^{\circ}$ 53/2020 do CEE - Conselho Estadual de Ensino e a LDB (BRASIL, 1996), essa medida se justifica e deve ser conduzida diante da comprovada emergência sanitária decorrente da pandemia. E como forma e reconhecimento da lei, o artigo 32 afirma que

\footnotetext{
$\int 4^{\circ}$ "O ensino fundamental será presencial, sendo o ensino a distância utilizado como complementação da aprendizagem ou em situações emergenciais".

E \11" para efeito de cumprimento das exigências curriculares do ensino médio, os sistemas de ensino poderão reconhecer competências e firmar convênios com instituições de educação a distância com notório reconhecimento, mediante as seguintes formas de comprovação: VI - cursos realizados por meio de educação a distância ou educação presencial mediada por tecnologias. (Incluído pela Lei no 13.415 , de 2017).
}

Com base nos documentos legais, o Ministério da Educação divulgou que a situação já é considerada uma catástrofe mundial, não tendo precedentes na história pós guerra, e

\footnotetext{
${ }^{6}$ Aguardando homologação do Ministério da Educação.
} 
então a Proposta de Parecer do Conselho Nacional de Educação (Citada na tabela 2) sugeriu medidas para sanar o prejuízo com a pandemia mundial no ensino fundamental e médio:

- aulas gravadas pela televisão organizadas pela escola de acordo com o planejamento de aulas e conteúdos ou via plataformas digitais de organização de conteúdos;

- sistema de avaliação realizado a distância sob a orientação das escolas e dos professores e, quando possível, com a supervisão dos pais acerca do aprendizado dos seus filhos;

- lista de atividades e exercícios, sequências didáticas, trilhas de aprendizagem por fluxo de complexidade relacionadas às habilidades e aos objetos de aprendizagem;

- orientações aos pais para realização de atividades relacionadas aos objetivos de aprendizagem e habilidades da proposta curricular;

- guias de orientação aos pais e estudantes sobre a organização das rotinas diárias;

- sugestões para que os pais realizem leituras para seus filhos;

- utilização de horários de TV aberta para levar programas educativos compatíveis com as crianças desta idade e orientar os pais para o que elas possam assistir;

- elaboração de materiais impressos compatíveis com a idade da criança para realização de atividades (leitura, desenhos, pintura, recorte, dobradura, colagem, entre outros);

- distribuição de vídeos educativos (de curta duração) por meio de plataformas on-line, mas sem a necessidade de conexão simultânea seguidos de atividades a serem realizadas com a supervisão dos pais;

- realização de atividades on-line síncronas, regulares em relação aos objetos de conhecimento, de acordo com a disponibilidade tecnológica;

- oferta de atividades on-line assíncronas regulares em relação aos conteúdos, de acordo com a disponibilidade tecnológica e familiaridade do usuário;

- estudos dirigidos com supervisão dos pais;

- exercícios e dever de casa de acordo com os materiais didáticos utilizados pela escola;

- organização de grupos de pais por meio de aplicativos de mensagens instantâneas e outros conectando professores e as famílias; e

- guias de orientação às famílias e acompanhamento dos estudantes (BRASIL, 2020. p. 7-8).

Este momento nos parece desafiador, pois essa modalidade de ensino a distância por meio digitais era uma exclusividade do ensino superior. E em meio à pandemia, as famílias, professores e alunos da educação básica foram obrigados a se adequar e administrar essa nova modalidade de ensino aprendizagem. Moraes e Pereira (2009, p. 65) afirmam que

a educação a distância rompe com a relação espaço/tempo, que tem caracterizado a escola convencional, e se concretiza por intermédio da comunicação mediada, por meio da mídia. Diferentemente de uma situação de aprendizagem presencial, onde a mediação pedagógica é realizada pelo professor em contato direto com os alunos, na modalidade a distância a mídia torna-se uma necessidade absoluta para que se concretize a comunicação educacional. 
Historicamente, no Brasil, a Educação a distância emerge de uma necessidade de atender as demandas da globalização, que buscam preencher as lacunas de formação inicial, continuada e também uma educação não formal encontrada na sociedade contemporânea. Essa modalidade apresenta-se como uma alternativa de formação profissional em um país com grandes dimensões geográficas e sérias desigualdades regionais (JUNIOR, 2009; MORAES; PEREIRA, 2003).

Os avanços tecnológicos das últimas décadas propiciaram uma nova perspectiva para o ensino a distância no país. Novas ações foram criadas, principalmente para a formação de professores, pensando em suprir a carência nas regiões mais necessitadas, já que todos os professores da educação básica deveriam ter formação superior atendendo as exigências do artigo 62 da LDB.

À medida que a EaD progrediu no Brasil, inúmeros estudos e reflexões foram realizados acerca dessa modalidade (KENSKI, 2010; ARRUDA; ARRUDA, 2015). Para Orso (1996), há pouca interação entre aluno e professor, uma vez que só o professor fala, o que corresponde a uma educação acrítica, desprovida de uma prática democrática.

Segundo Freire (1987, p. 34), esse tipo de educação, que ele classifica como bancária, visa submeter os educandos “à memorização mecânica do conteúdo narrado". Mais ainda, a narração transforma-os em "vasilhas", recipientes a serem "enchidos" pelo educador". Portanto, esse ambiente interativo não propicia espaços para discussões entre os atores do processo, tornando o ambiente unidirecional, indo na contramão do modelo da sala de aula presencial, em que o contato direto entre professores e alunos é muito forte porque apresenta o mesmo tempo e espaço (KENSKI, 2010).

Discute-se, também, que a $\mathrm{EaD}$ não se configura como um espaço de democratização, pois não existem dados que esclareçam sobre a sua qualidade e reconhecimento das especificidades de seus alunos, visto que "ela é recomendada como forma de interiorizar a educação e ampliar o acesso da população" (ARRUDA; ARRUDA, 2015, p. 334). Segundo as autoras, a EaD precisa sair da "política emergencial e assumir um papel de organização sólida, que envolva pesquisa e extensão, visto que ela é tratada hoje pelas políticas brasileiras por ações de barateamento e massificação da educação superior no país (ARRUDA; ARRUDA, 2015). Diante dessas dificuldades apresentadas em seu processo histórico, refletidas até hoje, questiona-se a inserção dessa modalidade na educação básica em época de pandemia.

Dessa forma, segundo dados da Revista Abril em um relatório divulgado pela Unesco, órgão da ONU para a educação e cultura, 300 milhões de alunos, 22 países e 3 
continentes foram afetados pela pandemia. Esses números só cresceram com o avanço da contaminação pelo mundo. Só na Bahia, conforme citado anteriormente, mais de 800 mil alunos da rede estadual estão sem aula nesse momento. Não se sabe ao certo, e não se tem respostas precisas sobre quais os impactos na vida de professores, alunos e de todos envolvidos.

Casagrande (2020), em entrevista, ressaltou que o uso das novas tecnologias como forma de ensino aprendizagem é uma ferramenta já utilizada no ensino superior e, em tempos de pandemia, serve como reparação de danos aos alunos durante a propagação do vírus. Entretanto, o uso dessas mesmas tecnologias na educação básica é um problema maior, porque as escolas não estão preparadas, mas ele defende que as instituições de ensino mais rapidamente devem utilizar e se adaptar a essas novas tecnologias. Em contrapartida, deparamo-nos com mais um problema, para que essas práticas sejam efetivas e democráticas, ele defende que é necessário que todos os alunos tenham acesso à internet. Em 2018, segundo pesquisa TIC domicílio, 30\% dos lares brasileiros não possuem internet, na sua maioria as residências de pessoas mais pobres. Para Casagrande (2020), essa questão vai acentuar a diferença de classes. A rede privada vai encontrar algumas soluções que demandam recursos financeiros, o que, para a escola pública, é muito mais difícil. Desse modo, os alunos do sistema público devem sentir mais os impactos.

\section{CONSIDERAÇÕES FINAIS}

Estamos vivendo tempos difíceis com o COVID-19, a pandemia contemporânea mostra-se globalizada e expõe que é necessário desenvolver, urgentemente, políticas públicas de igualdade educacional, pensando em ações voltadas para a preservação da dignidade, identidade cultural, do respeito à diferença e inclusão dos alunos, que encontram-se nesse momento privados do direito que é garantido pela Constituição Federal.

Muitos são os desafios e (im)possibilidades para a prática docente no atual contexto, observa-se que os professores e professoras são mais consumidores da tecnologia que produtores. Esse fato se deve ao modelo de formação inicial que precisa ser pensado/ adaptado para a contemporaneidade.

A EaD foi implementada no Brasil para contemplar demandas de formação inicial de professores. Há muito a se fazer para a EaD funcionar na Educação Básica, uma vez que não é configurada como espaço de democratização. Muitos alunos e alunas não 
possuem acesso à internet e não dispõem de espaço adequado para o desenvolvimento de estudos nas residências.

Mesmo com esses enfrentamentos e desafios, a Educação resiste! Resiste, quando observamos um número significativo de professores e professoras, que mesmo não sendo preparados, rendem-se ao desafio de uma nova prática pedagógica, ao preparar vídeos e atividades on-lines; resiste, quando pensamos em estratégias para serem desenvolvidas com os alunos que não possuem acesso às tecnologias; resiste, quando são publicados documentos oficiais de Educação apresentando orientações sobre possibilidades de ensino e aprendizagem nesse contexto; resiste, quando pensamos no momento atual, em que o objetivo maior é combater o vírus e preservar vidas.

\section{REFERÊNCIAS}

ARRUDA, Eucidio Pimenta; ARRUDA, Durcelina Ereni Pimenta. Educação à distância no Brasil: políticas públicas e democratização do acesso ao ensino superior. Educação em Revista, v. 31, n. 3, p. 321-338, 2015.

BAHIA. Parecer do Conselho Estadual de Educação. Normas para o funcionamento das Instituições de Ensino integrantes do Sistema Estadual de Ensino da Bahia no período de situação de emergência de prevenção e enfrentamento ao COVID-19. Número: 53/2020. Disponível em http://www.conselhodeeducacao.ba.gov.br. Acessado em 20 de abril de 2020.

BRASIL. Decreto Lei no 1.044, artigo $2^{\circ}$ de 21 de outubro de 1969. Brasília, 1969.

BRASIL. Constituição Federal de 1988. Brasília, 1988.

BRASIL. MEC. Lei de Diretrizes e Bases da Educação Nacional. LEI No 9394 de 20 de dezembro de 1996.

BRASIL. Lei $\mathrm{n}^{\circ}$ 13.415, de 16 de fevereiro de 2017. Disponível em http://www.planalto.gov.br/. Acessado em 20 de abril de 2020.

BRASIL. Portaria no 343, de 17 de março de 2020. Dispõe sobre a substituição das aulas presenciais por aulas em meios digitais enquanto durar a situação de pandemia do Novo Coronavírus - $\quad$ COVID-19. Disponível em http://www.planalto.gov.br/CCIVIL_03/Portaria/PRT/Portaria $\% 20$ n\%C2\%BA $\% 20343$ 20-mec.htm. Acessado em 30 de abril de 2020.

CASAGRANDE, R. Coronavírus no Brasil: como a pandemia prejudica a educação. Entrevista concedida à revista eletrônica Guia do Estudante. Disponível em: https://guiadoestudante.abril.com.br/atualidades/coronavirus-no-brasil-como-apandemia-prejudica-a-educacao/. Acessado em: 23 de Abril 2020.

FREIRE, Paulo. Pedagogia do oprimido. 17. ed, Rio de Janeiro: Paz e Terra. 1987. 
FREITAS, A. Donaliso, M. R. Napimoga, M.. Análise da gravidade da pandemia de Covid19. Artigo de opinião. Dol: 10.5123/S1679-497400000 200008. p. 1-5. Universidade Estadual de Campinas, Departamento de Saúde Coletiva, Campinas, SP, Brasil. Epidemiol. Serv. Saude, Brasília, 2020.

JUNIOR, K. S. Educação a distância no Brasil: caminhos, políticas e perspectivas. ETDEducação Temática Digital, v. 10, n. 2, p. 16-36, 2009. Disponível em: https://periodicos.sbu.unicamp.br/ojs/index.php/etd/article/view/975. Acesso em 20 de abril de 2020.

KENSKI, V. M. O desafio da Educação a Distância no Brasil. Revista Edu foco. V. 7, Juiz de Fora. p. 1-13, 2010.

MACEDO, Yuri Miguel. ORNELLAS, Joaquim Lemos. BONFIM. Helder reitas. COVID19 NO BRASIL: o que se espera para população subalternizada? INSS 2675-1291- DOI: http://dx.doi.org/10.5935/encantar.v2.0001. Revista Encantar - Educação, Cultura e Sociedade - Bom Jesus da Lapa, v. 2, p. 01-10, jan./dez. 2020.

MORAES, Raquel Almeida; PEREIRA, Eva Waisros. A política de educação a distância no Brasil e os desafios na formação de professores na educação superior. In: SEMINÁRIO DO HISTEDBR. EIXO2. HISTÓRIA, POLÍTICAS PÚBLICAS E EDUCAÇÃO. 2009. Disponível em https://histedbrnovo.fe.unicamp.br/pfhistedbr/seminario/seminario8/_files/mBv36y8F.doc. Acesso em abril, 2020.

ORSO, Paulino José. A concepção de poder em Michel Foucault e as relações de poder na Universidade Estadual do Oeste do Paraná-Campinas. SP, 1996. Dissertação de Mestrado Universidade Estadual de Campinas. Faculdade de Educação.

SANTOS, Boaventura de Souza. A cruel Pedagogia do Vírus. ISBN 978-972-40-8496-1, CDU 347. 2020.

Recebido em 02 mai 2020.

Publicado em 10 mai 2020.

\footnotetext{
i Doutoranda em Educação - UFBA. Mestrado em Educação em Ciências - UESC. Possui Licenciatura em Pedagogia. Foi bolsista da Fundação de Amparo à Pesquisa do Estado da Bahia (FAPESB). Professora das disciplinas: Prática Pedagógica e Estágio Supervisionado na Universidade do Estado da Bahia, Campus XVIII. Integrante dos Grupos de Pesquisa: GRUPAC - Grupo de Pesquisa em Alfabetização Científica UESC e Infância, Educação e Contemporaneidade - UESB. Possui experiência na educação básica e ensino superior, atuando principalmente nos seguintes temas: Estágio supervisionado, Práticas Pedagógicas, Formação de Professores, Educação Infantil, Ensino de Ciências por Investigação e Desenvolvimento Profissional Docente.

ii Graduanda em Letras pela Universidade do Estado da Bahia - UNEB, campus XVIII, integrante do Grupo de Estudo em Linguística Aplicada e Transdisciplinaridade - GELAT , bolsista voluntária do Programa de Iniciação Científica intitulado "Pesquisas em Linguística Aplicada: o que dizem nossos currículos".
} 